\title{
Characterization of the secondary swelling of compacted Maryland clay
}

\author{
Shengyang Yuan ${ }^{1}$, Xianfeng Liu ${ }^{1, a}$, Scott Sloan ${ }^{1}$, Olivier Buzzi ${ }^{1}$ \\ ${ }^{1}$ Priority Research Centre for Geotechnical and Materials Modelling, School of Engineering, The University of Newcastle, NSW, Australia.
}

\begin{abstract}
This paper presents the result of a multi-scale experimental investigation on the phenomenon of secondary swelling. Specimens of compacted Maryland clay were prepared under different initial conditions (void ratio and water content), loaded at different levels of vertical stress and inundated until secondary swelling was observed. One test was also performed with suction control and incremental swelling. These tests were complemented by micro structural analyses via mercury intrusion porosimetry. The coefficient of secondary swelling, defined as the gradient of the evolution of void ratio with logarithm of time was calculated and correlated to the macro scale strain. Several trends were observed and it was showed that, under low confinement, the secondary swelling mostly takes place in the macro pores.
\end{abstract}

\section{Introduction}

Due to financial and environmental constraints, a number of roads projects in Australia have seen problematic expansive soils incorporated in road embankments. For example, an embankment of the Hunter expressway, located in the hunter valley, west of Newcastle, New South Wales, is made of about nine meters of expansive material over which about two and half meters of a capping layer have been placed. This layer is meant to provide a surcharge against swelling and prevent moisture ingress [1-2]. However, fluctuations of the water table level might lead to moisture movement in the embankment and swelling or collapse of the expansive material. In the core of the embankment, i.e. away from the areas sensitive to seasonal influence, the wetting process is likely to be slow and monotonic, similar than under a slab or a foundation [3]. With a tolerance to swelling, imposed by the road and maritime services, close to zero, it becomes relevant to consider both primary and secondary swelling in the analysis/prediction of the long term response of the embankment. To date, researchers attention has largely been focused on the primary swelling and there is little data on the secondary swelling [4].

This study investigates the swelling behaviour of compacted specimens of an Australian expansive soil with an emphasis on the secondary swelling phase. A large number of one-dimensional swelling tests under different vertical stress and initial conditions were performed. The response during incremental swelling, with a controlled reduction in suction, was also investigated. The macro scale observations were completed by a number of micro structural analyses.

\footnotetext{
${ }^{\mathrm{a}}$ Corresponding author: Xianfeng.Liu@newcastle.edu.au
}

\section{Materials}

A natural expansive clayey soil, coming from the field site of the University of Newcastle in Maryland, NSW, Australia, was used for this experimental investigation (see details in [5]). The soil is highly reactive with about $10 \%$ in mass of interlayered illite-smectite clay. The plasticity index of the material is about $45 \%$. More details regarding the characterization of the clay can be found in [5]. Crumbs of natural soil were dried at $105{ }^{\circ} \mathrm{C}$ and crushed to particles smaller than $1.18 \mathrm{~mm}$. Three batches of soil were then sprayed with water in order to reach three different target water contents $(13.2 \%, 17.8 \%$ and $21.4 \%)$. These values of water content correspond to suctions of $6.38 \mathrm{MPa}, 2.57 \mathrm{MPa}$ and $0.82 \mathrm{MPa}$, respectively. After an equilibration period of two weeks, the specimens were compacted at $0.5 \mathrm{~mm} / \mathrm{min}$ in an oedometer ring (diameter of $45 \mathrm{~mm}$, height of $19 \mathrm{~mm}$ ) using a load frame, in order to reach specific void ratios.

\section{Experimental facilities}

This study involves 3 series of tests. The first series investigated the effect of vertical stress, ranging from 6 $\mathrm{kPa}$ to $400 \mathrm{kPa}$ on the secondary swelling phase. For these tests, the void ratio was constant $\left(e_{o}=0.62\right)$ but three initial suctions were used. The second series of tests looked at the effect of the initial void ratio. Here, only one stress value was applied $(100 \mathrm{kPa})$ and one value of initial suction was used $(6.38 \mathrm{MPa})$. All tests were conducted using standard oedometers by flooding the specimens with distilled water. The final test to be conducted involves swelling with suction control by the 
osmotic method and a multistage reduction of suction. This test was conducted under a constant vertical stress of $6 \mathrm{kPa}$ with an initial void ratio of 0.62 and an initial suction of about $0.86 \mathrm{MPa}$. This last test was performed using the specific device depicted in Figure 1 with the suction generated by the osmotic system duly calibrated as in [6]. The apparatus was placed in a controlled temperature environment $\left(20^{\circ} \mathrm{C} \pm 0.1^{\circ} \mathrm{C}\right)$ and the suction generated was estimated using the equation provided in [7]:

$$
s=11 c^{2}
$$

where $s$ is the suction in MPa and $c$ is the PEG concentration in grams of PEG per gram of water. A thin layer of paraffin oil was placed on top of the PEG solution to prevent evaporation.

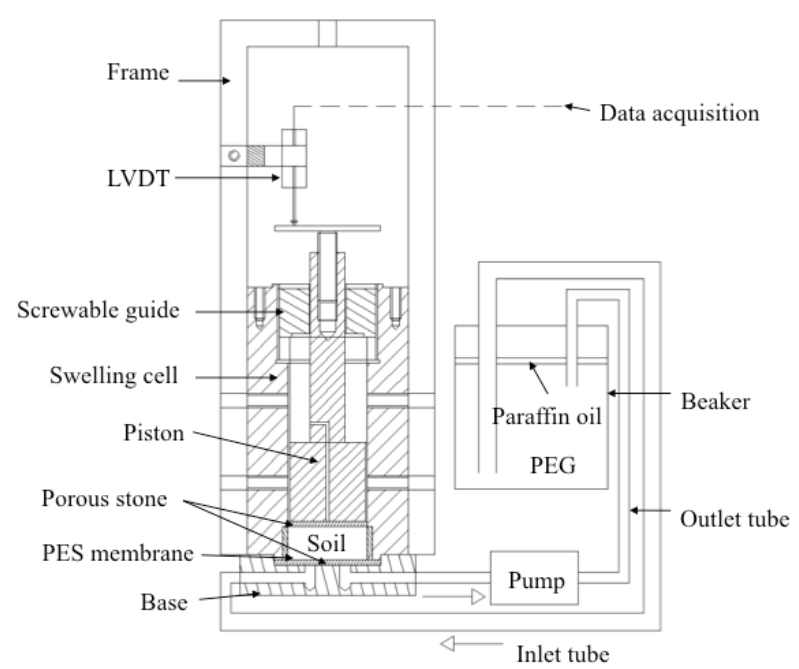

Figure 1 Sketch of the swelling cell with osmotic control of suction.

The microstructural investigations were performed using mercury intrusion Porosimetry (MIP), which is based on the Laplace-Young's law, an equation that relates the capillary pressure $P_{\mathrm{c}}$ to the capillary radius $r$ :

$$
P_{c}=\frac{2 \gamma \cos \theta}{r}
$$

where $\theta$ is the contact angle between the liquid mercury and the solid surface $\left(140^{\circ}\right)$, and $\gamma$ is the mercury surface tension $(\gamma=0.482 \mathrm{~N} / \mathrm{m})$. The MIP apparatus is a Micromeritics AutoPore IV 9500 with a maximal pressure of $228 \mathrm{MPa}$ (yielding an equivalent entrance pore diameter of about $6.5 \mathrm{~nm}$, as per equation 2 ).

Some Scanning Electron Microscope (SEM) images were obtained using a Zeiss Sigma VP FESEM (Bruker light element SSD EDS detector). For this part, specimens were broken rather than cut in order to avoid a "smearing effect". Also, for better imaging contrast, the undisturbed surfaces of specimens were coated with gold under vacuum. It is essential to remove all moisture from the soil specimens for meaningful SEM and MIP analysis. This was achieved by a freeze-drying process where the "freeze" phase consists of immersing small $\left(0.5 \mathrm{~cm}^{3}\right)$ soil pieces in liquid nitrogen while the "drying phase" consists of sublimating the amorphous ice formed in the freeze phase using a freeze-dryer (Christ ${ }^{\circledR}$ ALPHA 1-2). This latter process lasts at least 48 hours, after which no moisture uptake should be permitted. Consequently, all specimens were sealed in airtight plastic containers bottles and stored in a desiccator containing dessicant gel.

\section{Results and discussion}

\subsection{Inundation tests}

Figure 2 shows the typical evolution of swelling strain with time for compacted specimen swelling under different loads. The phases of primary and secondary swelling are clearly visible and, consistent with other studies of the literature, the higher the vertical stress, the lower the swelling strain. Note that collapse was observed for vertical stresses of 300 and $400 \mathrm{kPa}$ for initial suctions of $2.57 \mathrm{MPa}$ and $0.82 \mathrm{MPa}$. This is later reported as a negative swelling strain.

The response illustrated in Figure 2 can be used to compute the coefficient of secondary swelling $C_{\alpha S}$ defined as:

$$
\mathrm{C}_{\alpha \mathrm{s}}=\frac{\Delta \varepsilon}{\Delta \log _{10}(t)}
$$

where $\Delta \varepsilon$ is the change in swelling or compression strain between the end of primary (EOP) swelling and any hydration time $t$ larger than the time required to reach EOP.

Figure 3 shows the evolution of $C_{\alpha s}$ with the magnitude of vertical stress for three different initial suctions (Figure $3 a)$. Consistent with the general response of Figure 2, the higher the stress, the lower $C_{\alpha s}$. For a given stress level, $C_{\alpha s}$ is also found to increase as the initial suction increases. The effect of the void ratio is shown in Figure 3b. $C_{\alpha s}$ progressively drops from 1.4 to about 0 as the void ratio increases from 0.47 to 0.82 . These tests suggest that the behaviour in the secondary swelling is fully consistent with that of the primary swelling. Based on these results, an attempt was made to correlate the coefficient of secondary swelling to the swelling strain at the end of primary swelling (EOP). Fitting the data (see Figure 4) returned a $R^{2}$ coefficient of 0.88 :

$$
C_{\alpha}=0.135 e^{\left(\frac{\varepsilon_{E O P}}{3.9}\right)}-0.08
$$

Note that the magnitude of final strain reflects the initial specimen conditions (void ratio and suction) and the level of confinement (vertical stress). Consequently, these parameters do not need to appear explicitly in the equation. The correlation can then be used to estimate the magnitude of swelling occurring in the secondary phase 


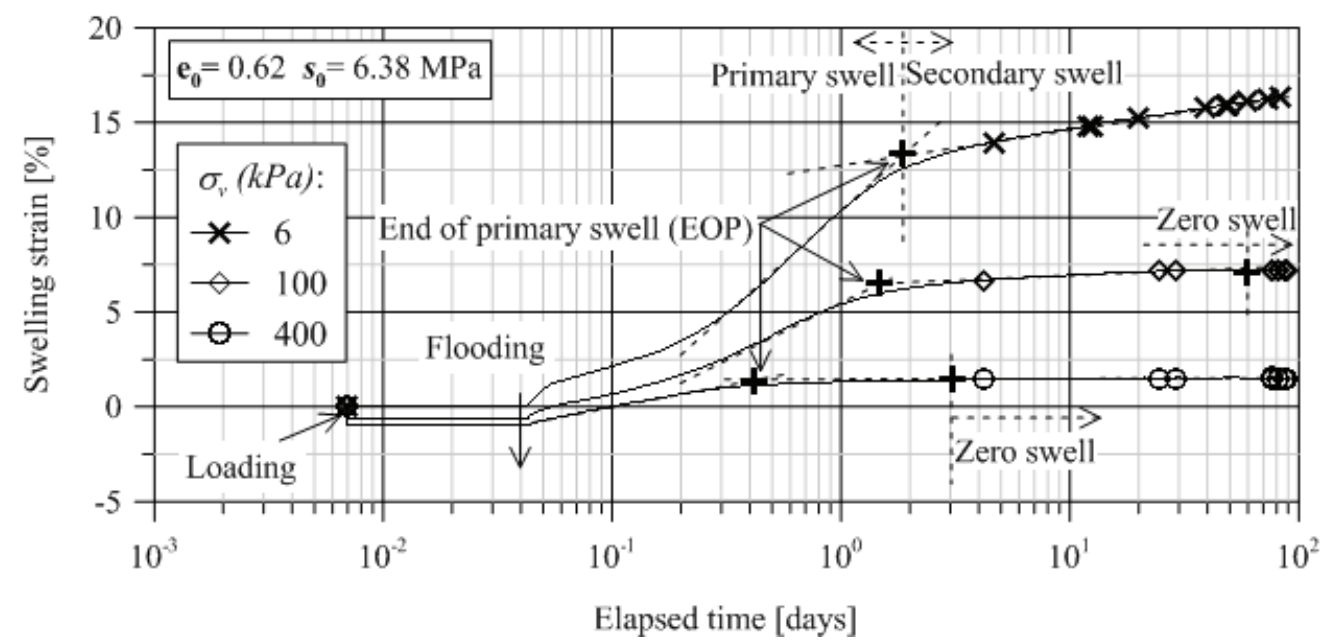

Figure 2. Swelling curves for compacted Maryland clay at $e_{0}=0.62$ and $\mathrm{s}_{0}=6.38 \mathrm{MPa}$ subjected to flooding under 6,100 and 400 $\mathrm{kPa}$.

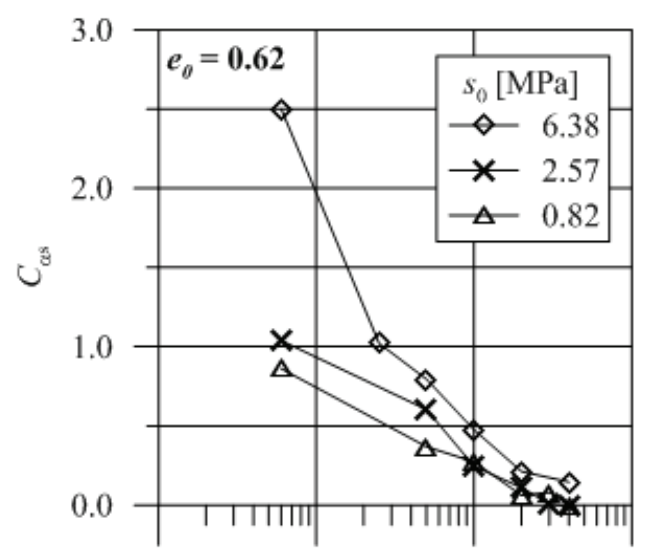

$$
10^{0} \quad 10^{1} \quad 10^{2} \quad 10^{3}
$$

Vertical pressure, $\sigma_{v}^{\prime}(\mathrm{kPa})$

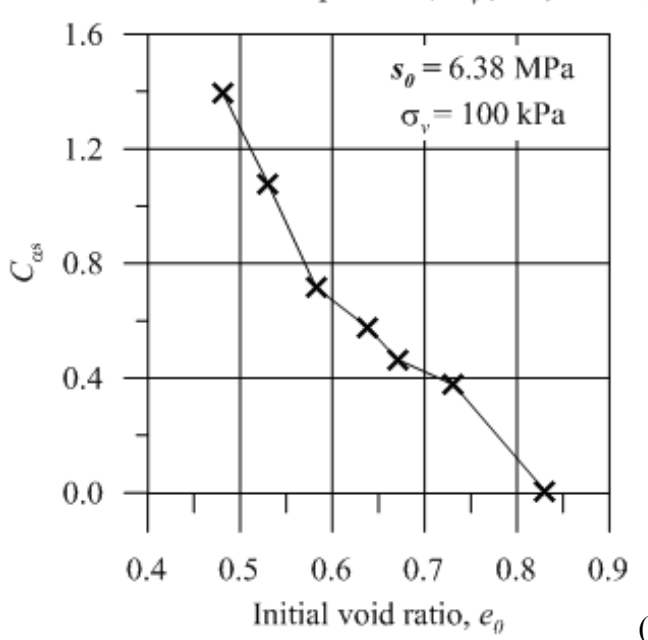

(a)

Figure 3: Evolution of $C_{\alpha s}$ with applied vertical pressure (a) and with the initial void ratio (b).

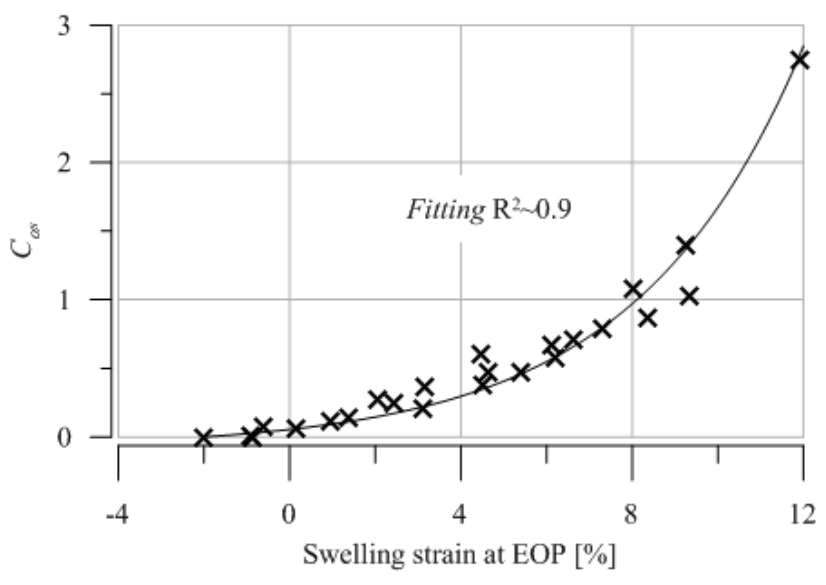

Figure 4 Evolution of $C_{\alpha s}$ with swelling strain at the end of primary swelling (EOP) for compacted ML samples at different initial states.

\subsection{Incremental swelling}

The incremental swelling test, performed under $6 \mathrm{kPa}$, also shows occurrence of secondary swelling (see Figure 5 ). Note that the first stage of the test (for a suction of $860 \mathrm{kPa}$ ) is an equilibration phase not resulting in swelling. The results presented in Figure 5 are consistent with existing data of the literature (e.g. [8]).

The coefficient of secondary swelling was estimated at the various stages of hydration and plotted as a function of the suction at the beginning of each stage and swelling strain occurring for each stage. Results are showed in Figure 6 . The coefficient of secondary swelling appears to be increasing linearly with the imposed suction. Again, this is consistent with the response during primary swelling (see Figure 5). However, the $C_{\alpha s}$ values associated with incremental swelling do not align with those coming from the inundation tests. This is evidenced in Figure $6 \mathrm{~b}$ where Equation 2 is represented by a dashed line. This might be due to different swelling mechanisms occurring at different stages of the overall swelling 
process but of the changes in hydration procedure. At this stage, this is not fully explained yet.

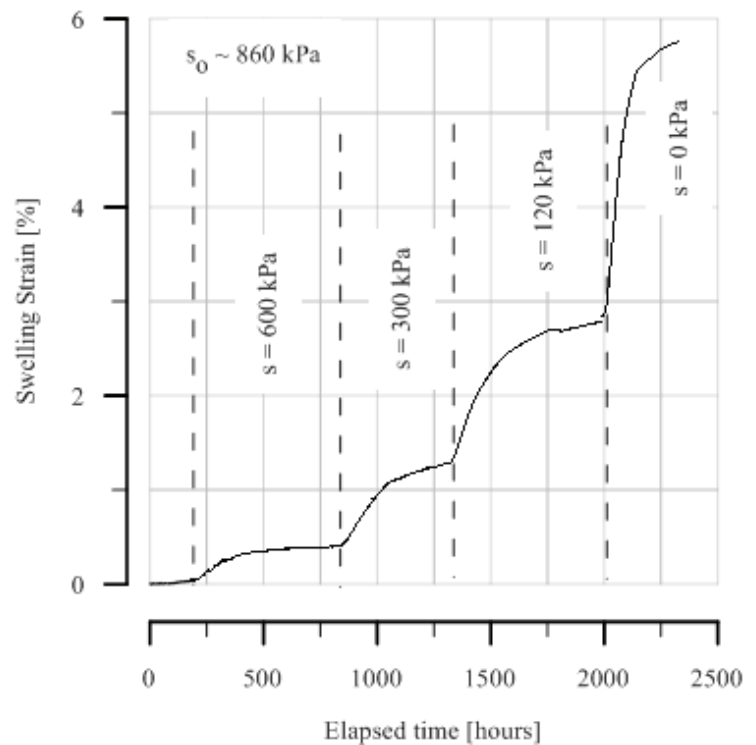

Figure 5. Evolution of swelling strain in time as suction is incrementally reduced from $860 \mathrm{kPa}$ to $0 \mathrm{kPa}$. Initial void ratio $e_{o}=0.62$.
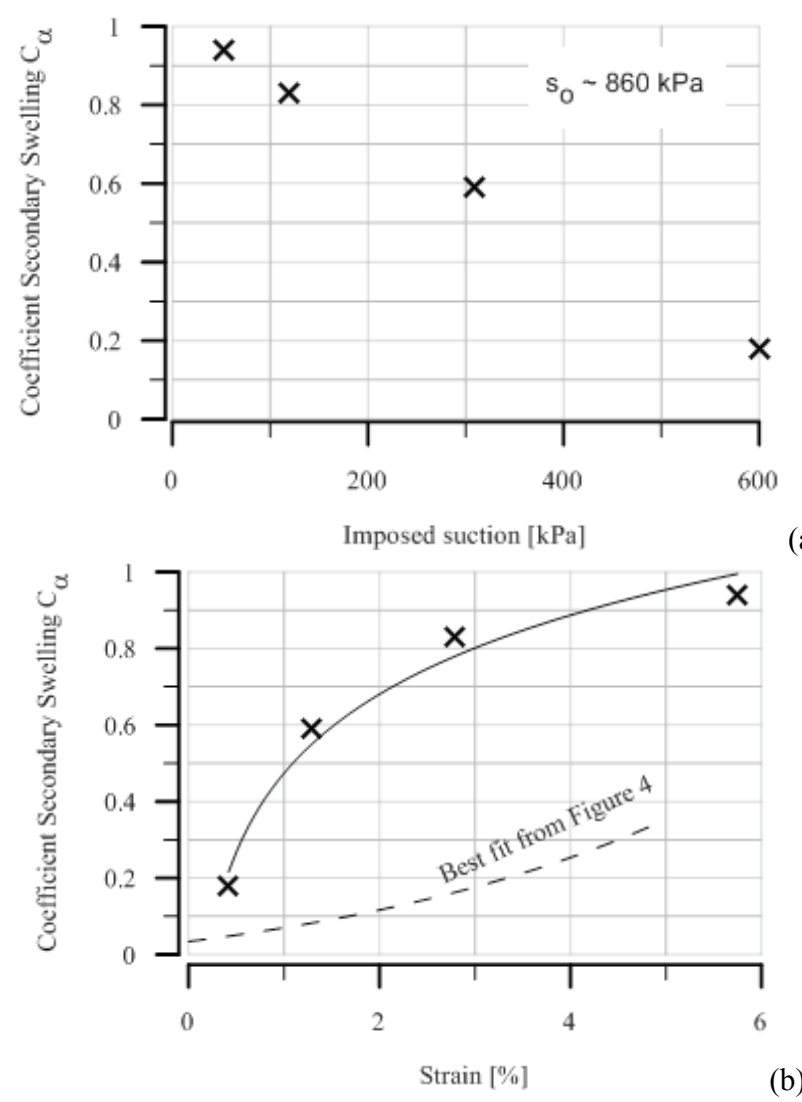

(a)

Figure 6. Evolution of $C_{\alpha S}$ with the imposed suction (a) and with the swelling strain at the end of primary swelling at various stages of the incremental swelling test (b). Initial suction of about $860 \mathrm{kPa}$ and initial void ratio of 0.62 .

\subsection{Evolution of pore size distribution}

The initial pore size distributions (PSD) pertaining to three different initial states are shown in Figure 7. The curves show a clear influence of the initial suction on the compaction process and the resulting bimodal microstructure. Increasing the initial suction tends to reduce the size of the predominant pores, both at macro and micro levels. However, the effect of initial suction on the frequency of predominant pores is opposite at macro and micro scale.

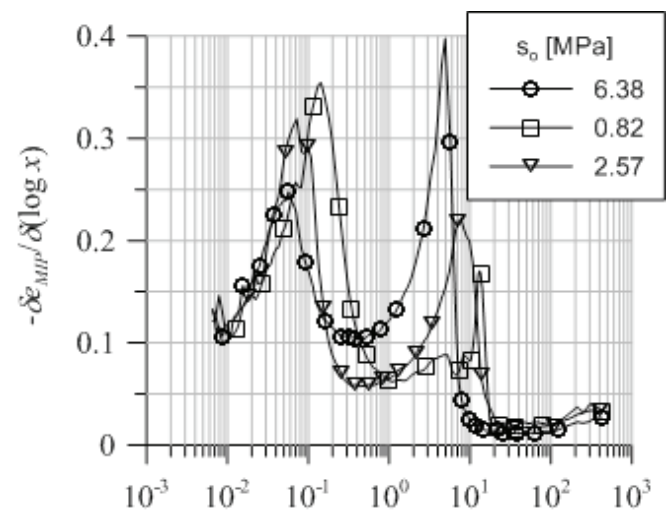

Entrance pore diameter, $x(\mu \mathrm{m})$

Figure 7. Pore size distribution of Maryland clay specimens compacted to a void ratio of 0.62 with an initial suction of 0.82 , 2.57 and $6.38 \mathrm{MPa}$.
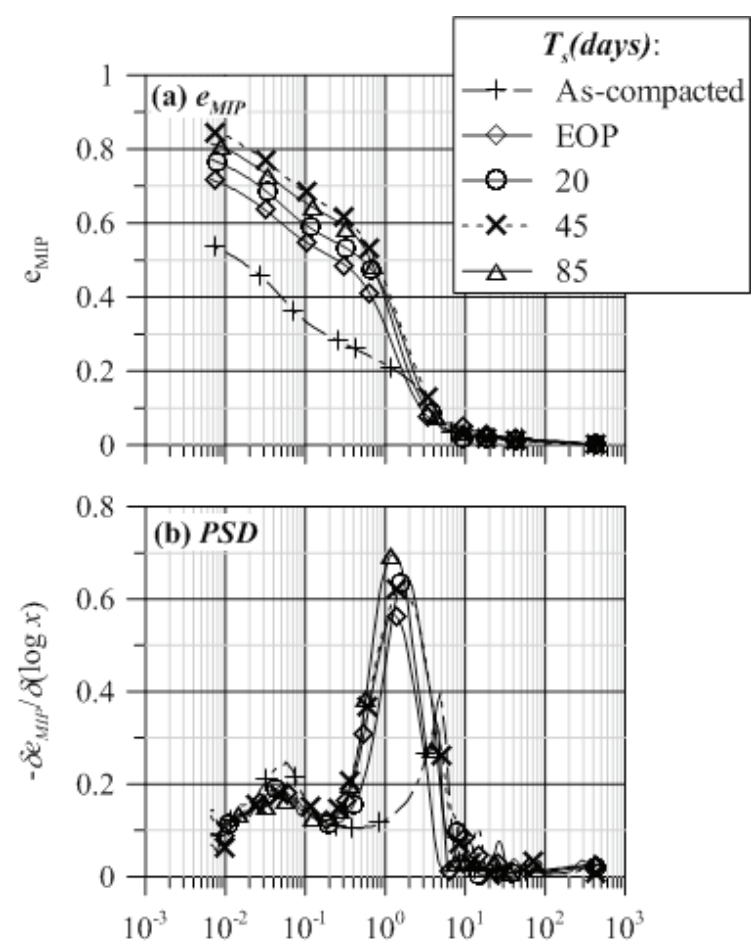

Entrance pore diameter, $x(\mu \mathrm{m})$

Figure. 8 MIP results in terms of mercury intrusion void ratio, $\mathrm{e}_{\text {MIP }}$ (a) and pore size distribution (b) for compacted samples prepared at $e_{o}=0.62, s_{o}=6.38 \mathrm{MPa}$ and subjected to a vertical stress $\sigma_{v}$ of $6 \mathrm{kPa}$.

One swelling test was conducted with several parallel specimens in order to conduct MIP analysis at various 
stage of the swelling process. This test pertains to the following initial conditions: $e_{o}=0.62, s_{o}=6.38 \mathrm{MPa}$ and $\sigma_{v}=6 \mathrm{kPa}$. The results show a clear decrease in predominant pore size as a result of the swelling process, which has already been observed in the literatures. Interestingly, this peak does not seem to shift during secondary swelling. Also, most of the microstructural changes seem to be occurring in the macro pores after EOP.

Finally, some SEM images taken prior and after 2 days (EOP) and 85 days swelling tests show a strong modification of the specimen structure. While the initial structure is clearly aggregated (see Figure 9a), the structural aggregation tends to be significantly reduced at end of primary swelling (Figure 9b) until that the final structure appears to have been smeared. The aggregates have swollen and filled the inter-aggregates pores yielding a more uniform structure (Figure 9c). A similar final structure was observed from a vertical stress of 100 $\mathrm{kPa}$. Note that the final soil structure, as shown in Figure 9 , is the result of the final swelling process, i.e. primary and secondary phases.
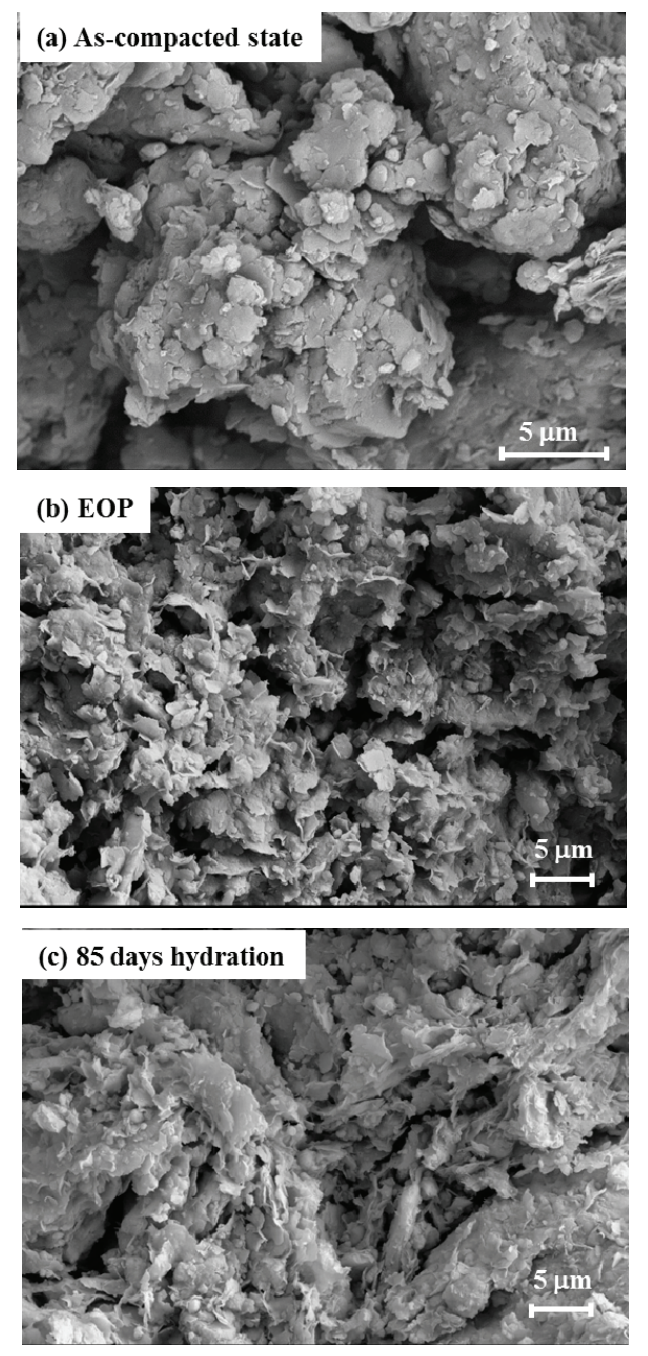

Figure 9. SEM images taken on compacted specimens $\left(e_{0}=\right.$ 0.62 and $s_{0}=6.38 \mathrm{MPa}$ ) right after compaction (a), at end of primary swelling (b) and after 85 days hydration under $6 \mathrm{kPa}$ (c).

\subsection{Discussion on multiscale coupling behaviour}

The mineralogy analysis shows that ML clay consists of both swelling and non-swelling minerals [5]. When the compacted ML samples were subjected to a decrease in imposed suction, the swelling minerals, for instance illitesmectite interlayered clay, within the clay aggregates expanded, leading to the expansion of the whole aggregate and in turn a decrease in the magnitude of structural aggregation (Figure 9). Consequently, the dominant pore size of intra-aggregate pores increases while that of inter-aggregate pores decreases due to the invasion of aggregates (Figure 8). As a result of the swelling occurring at the microscale, the swelling strain progressively developed (Figure 2 and 5). More swelling strain seems to take place at low suction range (Figure 5). The changes associated with swelling at both micro- and macro-scale appear to have occurred mainly during the primary swelling stage (prior to EOP). Moreover, the subsequent hydration during the secondary swelling stage leads to a microstructural homogenization (Fig.9c) and only a small increase in peak density of PSD without affecting much the dominant pore size.

As shown by the previous studies [9-13], the occurrence of swelling of expansive minerals consists of the development of crystalline swelling and osmotic swelling, which is associated with the hydration of inter-layer and interparticle pore spaces, respectively. In case of $\mathrm{Na}$ dominated bentonites, the crystalline swelling may widen the basal spacing, accommodating up to 4 layers of water molecules, while the osmotic swelling is mainly related to the formation of electrical diffuse double-layers [1012]. These swelling mechanisms may cause a significant breakdown of the clay particles made up of several hundreds of stacked unit layers when the adsorbed interlayer water is more than two [11-12]. The complete separation of two swelling phenomena appears to be difficult since they can coexist as shown by Saiyouri et al. [11-13]. The predominance of the one over the other highly depends on the hydration conditions. For instance, in case of the incremental swelling (Figure 5), the crystalline swelling tends to fully develop at high suction range, which is followed by the occurrence of the osmotic swelling at low suction range. In order words, the water adsorption seems to take place in a progressive manner initially at interlayer space and then at interparticle space. However, in case of inundating the sample, the ingress of water may be initiated by the osmotic swelling at the boundaries of aggregates, likely resulting in a quick increase in swelling strain during the primary swelling phase. This process is followed by the crystalline swelling through water diffusion from inter-aggregate to intra-aggregate pore space, which plays an important role in the secondary swelling phase. The different swelling mechanisms involving in the two types of swelling tests may explain the difference in the swelling strain rate during the secondary swelling phase. For instance, the incremental swelling likely induces more important breakdown the clay particles and in turn an increase in the exposed surface sites of water adsorption. This may 
further enhance the swelling magnitude occurring during the secondary swelling phase.

\section{Concluding remarks}

This study investigates the response of compacted specimens of an expansive soil during the secondary swelling phase. A series of inundation swelling tests under constant vertical stress were performed on specimens prepared at different initial suctions and void ratios. These tests were complemented by one incremental swelling test with a suction control device. The behaviour during the secondary swelling was found to be consistent with the response during primary swelling. A very strong correlation was found between the coefficient of secondary swelling and the strain at the end of primary swelling, both for swelling until saturation and partial swelling. However, the trends pertaining to incremental swelling and inundation tests do not agree, which is not fully explained at this stage. The micro structural analyses show a strong effect of the initial suction on the pore size distribution of the compacted specimens. Also, it seems that, under $6 \mathrm{kPa}$ of normal stress, most microstructural changes occur in the macro pores during the secondary swelling phase.

\section{References}

1. O. Buzzi O, S. Fityus, R. Kingsland, S. Aryal ANZ 2012 Conf. proceedings, Melb. pp 1075-1080 (2012)

2. S. Aryal, R. Kingsland, D. Och et al. ANZ 2012 Conf. proceedings, Melb. pp 1304-1309 (2012)

3. J. Nelson and D. Miller. Expansive Soils: Problems and Practice in Foundation and Pavement Engineering. John Wiley and Sons, New York (1997)

4. G. Mesri, C.R. Ullrich, Y.K. Choi Géotechnique 28:281-307 (1978).

5. X.F. Liu, O. Buzzi, S.Y. Yuan, J. Mendes and S. Fityus. Can. Geo. Journal, 53: 1-17 (2016).

6. S.Y. Yuan, X.F. Liu and O. Buzzi. Paper submitted to the 3rd European Conference on Unsaturated Soils, Paris (2016).

7. P. Delage, M. Howat and Y.J. Cui. Eng. Geology, 50 (1-2): 31-48 (1998).

8. V. Escario and J. Saez. In: Proceedings of the Third International Conference on Expansive Soils. Vol. 1. Haifa, Israel, pp. 195-200 (1973).

9. R. Pusch and R. Yong. Microstructure of smectite clays and engineering performance, Taylor and Francis, New York (2006).

10. L. Liu. Prediction of swelling pressures of different types of bentonite in dilute solutions. Colloids Surf. A. Physicochem. Eng. Asp., 434, 303-318 (2013).

11. N. Saiyouri, P. Y. Hicher and D. Tessier. Microstructural approach and transfer water modelling in highly compacted unsaturated swelling clays. Mech. Cohesive-frictional Mater., 5(1), 41-60 (2000).

12. N. Saiyouri, P. Y. Hicher and D. Tessier. Experimental study of swelling in unsaturated compacted clays. Clay Miner., 39(4), 469-479 (2004).

13. P. Delage, D. Marcial, Y.J. Cui and X. Ruiz. Ageing effects in a compacted bentonite: a microstructure approach. Géotechnique, 56:291-304 (2006). 